\title{
A need to improve communications between the Canadian Thoracic Society and its members
}

\author{
Louis-Philippe Boulet MD FRCPC, President, Canadian Thoracic Society
}

$\mathrm{O}$ ver the past several years, the Canadian Thoracic Society (CTS) has significantly increased its activities. We realize that this increase in activity sometimes makes it difficult for members to keep up-to-date on the initiatives that the CTS undertakes. Furthermore, the CTS has evolved as a more proactive group than in the past, as shown by its many new activities and areas of involvement of the past few years. To continue our pursuit of growth in activity, we believe it is important to be able to communicate effectively with our members and other parties interested in CTS programs.

One of the privileged ways in which the CTS communicates with its members is through the Canadian Respiratory Journal. Under the editorship of Dr Norman Jones, the Journal has become a very respected journal and source of information for the respiratory community in Canada. Dr Jones announced his retirement a few months ago. We are extremely grateful for his time, efforts and expertise with respect to the Journal, and are indebted to him for his superb work in making the Journal what it is today. The CTS wishes him a pleasant retirement.

Dr Nicholas Anthonisen, our renowned colleague, has accepted the role of Editor-in-Chief of the Journal, starting in January of 2002. Dr Anthonisen has had a very successful career, and is considered by many to be one of the fathers of modern respiratory medicine in Canada. In addition to his achievements as a clinician, physiologist and scientist, he has been involved in medical education, most recently as Dean of the Faculty of Medicine at the University of Manitoba, Winnipeg, Manitoba. Dr Anthonisen has been the main investigator of many studies, including those key in the field of respiratory diseases such as The Lung Health Study (1). We look forward to his involvement with the Journal.

This fall, the CTS' Web page will be reconstructed, thanks to the work of Dr Helen Ramsdale, to make it more useful and up to date. The new site will feature key documents produced by the CTS, lists of activities, and other useful information and links. Because one of its major roles is to fulfill the needs of our members, the CTS is asking for some feedback and suggestions about the content on the Web site, or for other ways to improve this means of communication.

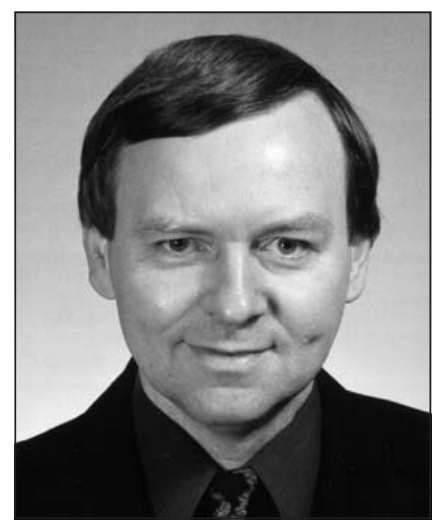

Another way to communicate with our members will soon be through a CTS Update that will be e-mailed every two months to members who register using a specific form posted on the Web page, or sent by fax. It will include, among other things, a relevant list of Canadian and international activities in respiratory diseases, specific Canadian conferences and workshops, and updates on initiatives that are most important to the Society (eg, updates on chronic obstructive pulmonary disease and asthma guidelines, and research activities and announcements). One section of the Update will deal with the state of collaborations with the American College of Chest Physicians and the American Thoracic Society. Hopefully, these different ways to communicate will help our members and collaborators remain informed about the progress of our many programs and activities.

\section{REFERENCE}

1. Anthonisen NR, Connett JE, Kiley JP, et al. Effects of smoking intervention and the use of an inhaled anticholinergic bronchodilator on the rate of decline in $\mathrm{FEV}_{1}$. The Lung Health Study. JAMA 1994;272:1497-505. 


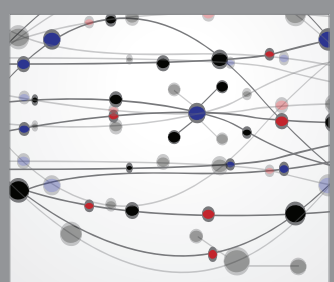

The Scientific World Journal
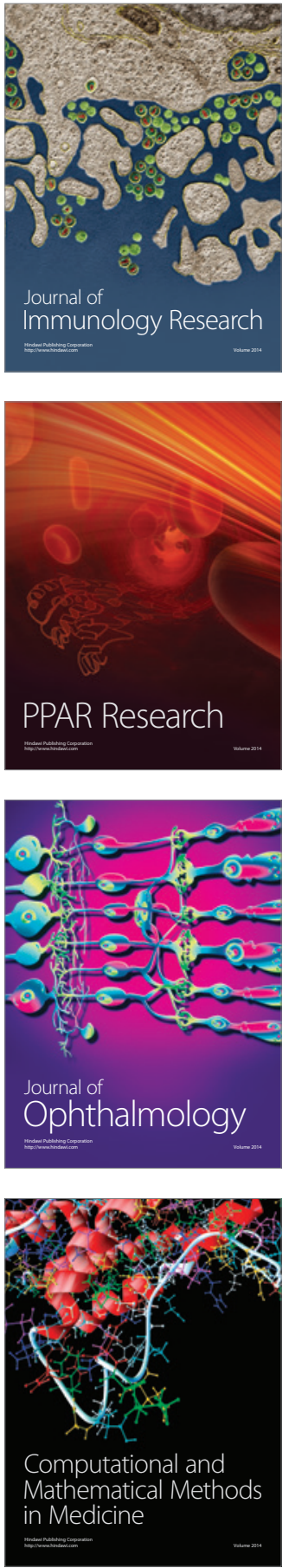

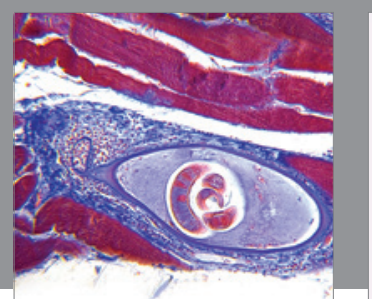

Gastroenterology Research and Practice

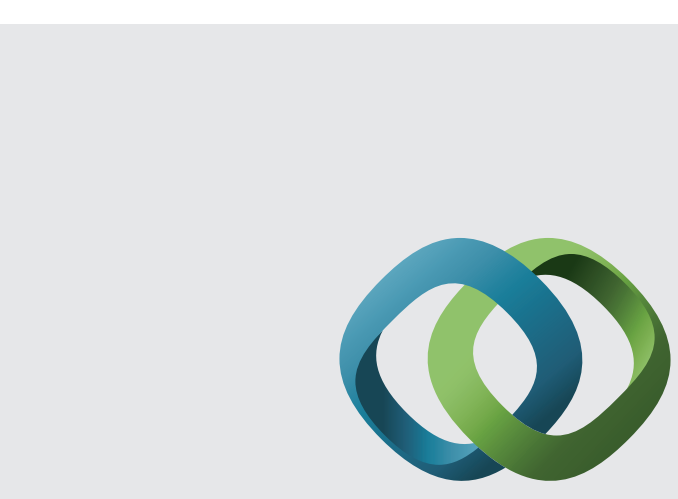

\section{Hindawi}

Submit your manuscripts at

http://www.hindawi.com
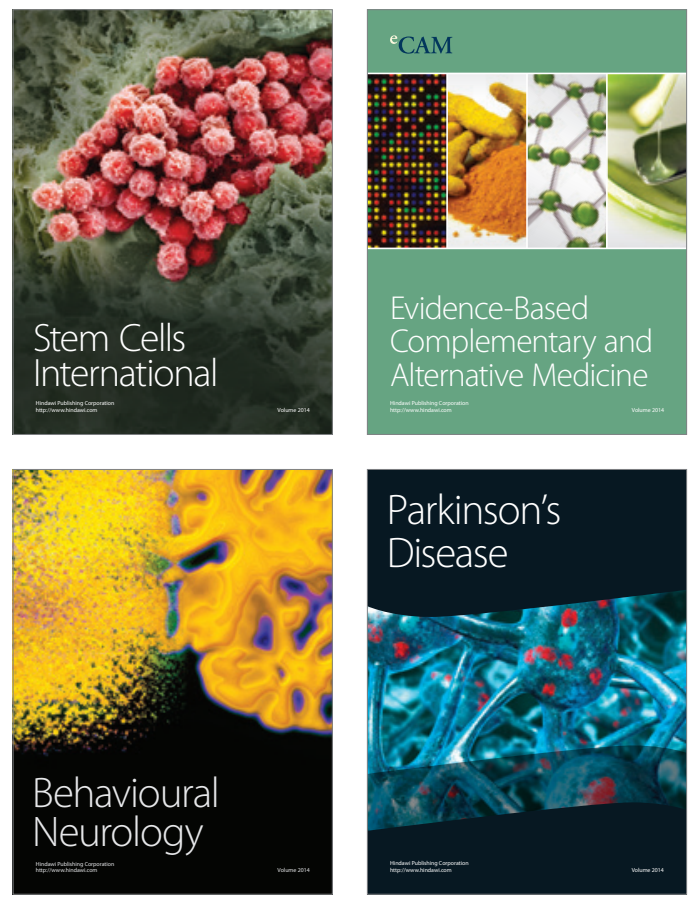
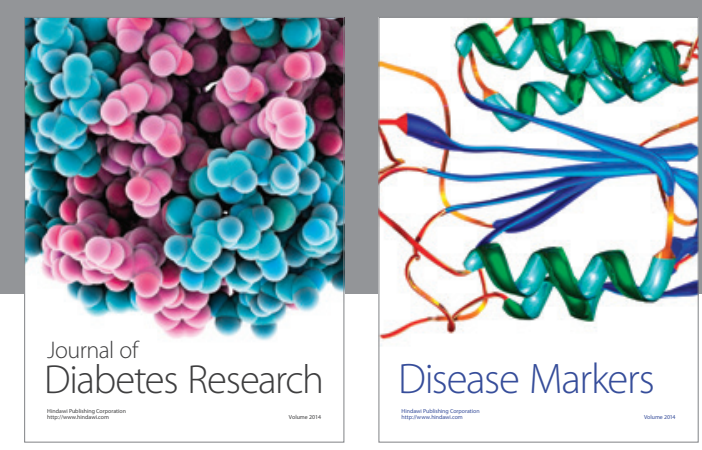

Disease Markers
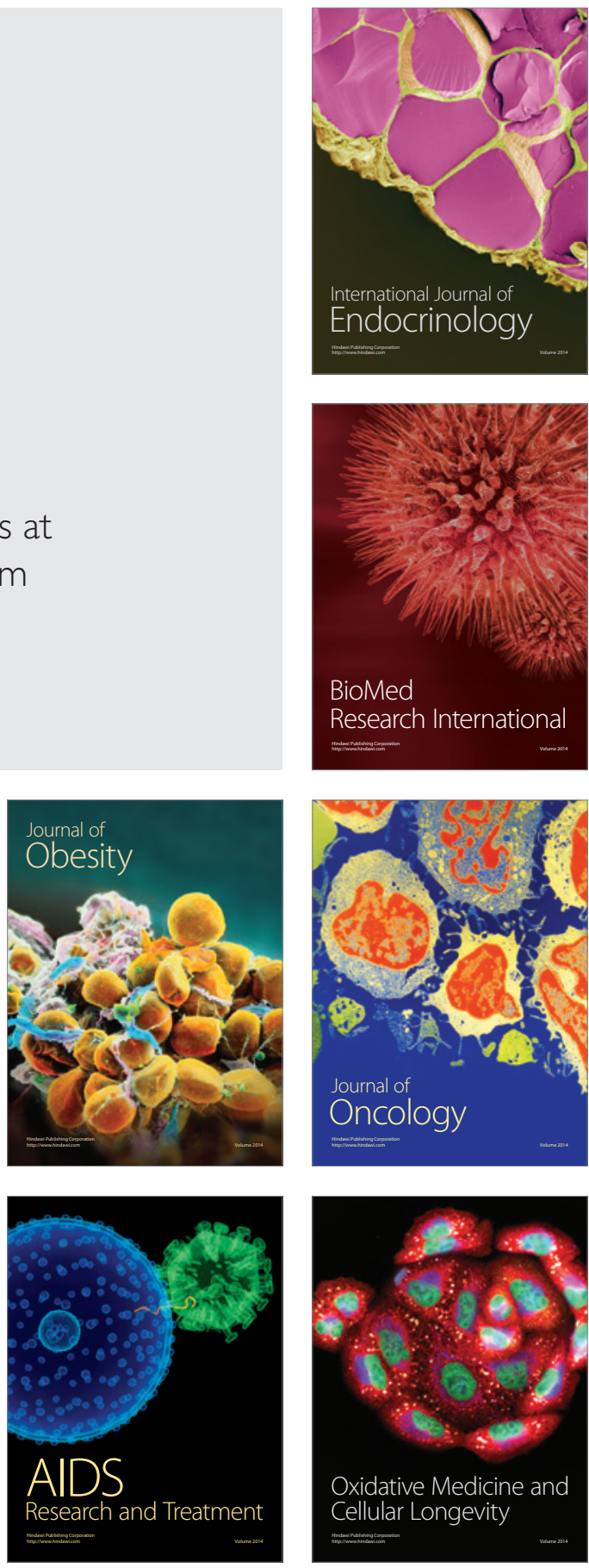